\title{
Studi Analisa Koordinasi Relai GFR Incoming Busbar 20 kV dan GFR Saluran Dalam Mengamankan Gangguan Satu Phasa Ketanah di Transformator 3 Gardu Induk Kapal
}

\author{
I Gede Krisnayoga Kusuma ${ }^{1}$ I Gede Dyana Arjana ${ }^{2}$, I Wayan Arta Wijaya ${ }^{3}$
}

\begin{abstract}
Disruption of the distribution system is generally caused by a short circuit that causes overcurrent, one single phase short circuit to ground. Single phase to ground disturbances that occurred at the feeder should be secured by GFR in peyulang. However, due to an error of coordination, interference with the feeder perceived also to the incoming side of the transformer so that the GFR in the incoming $20 \mathrm{kV}$ ordered PMT $20 \mathrm{kV}$ at the transformer side open. Working time ground fault relays in feeders Peguyangan is for 0.25 seconds. While working time in the incoming $20 \mathrm{kV} \mathrm{GFR}$ is for 0.5 seconds. This indicates that differences in work time relay by 0.25 seconds is considered selective. The event of disruption of the ground phase, GFR in securing regional coordination disorder should be gradual. Where the value of GFR at the base of working time should be longer than the working time GFR at feeders. It aims to GFR working order, so that errors can be avoided in the security and do not lead to the spread of disturbed areas. With the time difference of 0.25 , the relay can work in accordance with the working order and can protect its corresponding zone.
\end{abstract}

Intisari-Gangguan yang terjadi pada sistem distribusi umumnya disebabkan oleh hubung singkat yang menimbulkan arus lebih, salah satunya gangguan hubung singkat satu phasa ke tanah. Gangguan satu phasa ke tanah yang terjadi di penyulang seharusnya diamankan oleh GFR di peyulang. Namun karena kesalahan koordinasi, gangguan pada penyulang dirasakan juga sampai pada sisi incoming trafo sehingga GFR pada sisi incoming $20 \mathrm{kV}$ memerintahkan PMT sisi $20 \mathrm{kV}$ di trafo terbuka. Waktu kerja relai gangguan tanah di penyulang Peguyangan adalah selama 0,25 detik. Sementara waktu kerja GFR di incoming $20 \mathrm{kV}$ adalah selama 0,5 detik. Ini menandakan bahwa perbedaan waktu kerja relai sebesar 0,25 detik sudah dianggap selektif. Saat terjadi gangguan satu phasa ketanah, koodinasi GFR dalam mengamankan daerah gangguan harus secara bertahap. Dimana nilai waktu kerja GFR di pangkal harus lebih lama dari pada waktu kerja GFR pada penyulang. Ini bertujuan agar GFR bekerja sesuai urutannya, sehingga kesalahan dalam pengamanan dapat dihindarkan dan tidak mengakibatkan meluasnya daerah yang terganggu. Dengan adanya perbedaan waktu sebesar 0,25 , relai dapat bekerja sesuai dengan urutan kerja dan dapat melindungi sesuai zona kerjanya.

Kata Kunci-Sistem proteksi, OCR, GFR, Gangguan Satu Phasa.

\footnotetext{
${ }^{1}$ Mahasiswa, Teknik Elektro dan komputer Universitas Udayana, Kampus Bukit Jimbaran, Badung Bali. 80361, Tlp. 082145330553; e-mail: krisnayogak@gmail.com

${ }^{2,3}$ Dosen Jurusan Teknik Elektro dan Komputer Fakultas Teknik Universitas Udayana, Jln. Jalan Kampus Bukit Jimbaran 80361 INDONESIA. Telp: 0361-703315; fax: 0361-703315; e-mail: dyanaarjana@ee.unud.ac.id, artawijaya@unud.ac.id
}

\section{Pendahuluan}

Kebutuhan akan energi listrik terus menerus meningkat dari tahun ke tahun. Untuk memenuhi kebutuhan tersebut secara kuantitas dan kualitas maka dibutuhkan perencanaan sistem tenaga listrik yang tepat [1] dan adanya keandalan sistem tenaga listrik dalam mempertahankan kontinuitas penyaluran daya listrik. Keandalan pengamanan terhadap peralatan tenaga listrik sangat penting untuk meminimalisir kerusakan peralatan listrik. Berdasarkan data dari PT. PLN (Persero) Distribusi Bali, Indonesia selama tahun 2014 telah terjadi 3 kali gangguan hubung singkat yang menunjukkan indikasi terjadinya kesalahan pada koordinasi sistem proteksi hubung singkat [2].

Transformator merupakan peralatan yang sangat vital dalam penyaluran dan distribusi tenaga listrik. Dalam kondisi ini suatu transformator diharapkan dapat beroperasi secara maksimal, maka diperlukan sistem proteksi atau pengamanan yang andal pada sebuah transformator terhadap gangguan, terutama dari gangguan satu phasa ketanah agar tidak terjadi pemadaman [3].

Relai pengaman pada transformator untuk proteksi gangguan satu phasa ketanah pada sisi sekunder tranformator yaitu relai GFR (ground fault relai) busbar $20 \mathrm{kV}$ dan GFR saluran. GFR pada incoming busbar $20 \mathrm{kV}$ dipasang untuk mengamankan gangguan satu phasa ketanah yang terjadi pada busbar $20 \mathrm{kV}$, sedangkan GFR saluran yang dipasang berfungsi untuk merasakan gangguan satu phasa ketanah yang terjadi pada penyulang.

Gangguan satu phasa ketanah di penyulang Peguyangan pada tanggal 24 Januari 2013, seharusnya diamankan oleh GFR saluran dan GFR busbar $20 \mathrm{kV}$ pada kubikal. Namun karena kesalahan koordinasi, gangguan satu phasa ketanah pada penyulang Peguyangan dirasakan juga oleh SBEF dan REF pada transformator yang kemudian menginstruksikan PMT sisi $20 \mathrm{kV}$ pada transformator 3 GI Kapal untuk membuka sehingga mengakibatkan pemadaman kesemua penyulang yang di suplai oleh transformator 3 GI kapal.

\section{GFR DAN OCR}

Relai arus lebih adalah suatu relai yang bekerja hanya berdasarkan adanya kenaikan arus yang melebihi suatu nilai tertentu yang melewatinya. Selain mengamankan peralatan terhadap naiknya arus, relai pengaman ini harus juga dapat bekerja pada jangka waktu yang telah ditentukan sehingga pengaturan waktu dapat dikaitkan dengan masalah koordinasi pengaman. Berdasarkan adanya arus lebih yang dirasakan relai, baik disebabkan adanya gangguan hubung singkat atau overload (beban lebih) kemudian memberikan 
perintah trip ke-PMT sesuai dengan karakteristik waktunya. Pada kondisi normal arus lebih mengalir pada penyulang dan oleh trafo arus besaran arus ini ditransformasikan ke besaran sekunder. Arus mengalir pada kumparan relai tetepi karena arus ini masih lebih kecil dari pada suatu harga yang ditetapkan (setting), maka relai tidak bekerja. Bila terjadi gangguan singkat, arus akan naik dan menyebabkan arus naik melebihi suatu harga yang telah ditetapkan (diatas setting), maka relai akan bekerja dan membuka PMT, sehingga penyulang yang terganggu dipsahkan dari jaringan [4].

Relai hubung tanah yang lebih dikenal dengan GFR pada dasarnya mempunyai prinsip kerja sama dengan relai arus lebih (OCR) namun memiliki perbedaan dalam kegunaanya. Bila relai OCR mendeteksi adanya hubung singkat antara phasa, maka GFR mendeteksi adanya hubung singkat ke tanah. Pada kondisi normal beban seimbang Ir,Is,It sama besar, sehingga pada kawat netral tidak timbul arus dan relai tanah tidak akan teraliri arus. Bila terjadi ketidakseimbangan arus atau terjadi ganggunan hubung singkat ke tanah, maka akan timbul arus urutan nol pada kawat netral, sehingga relai hubung tanah akan bekerja.

Relai arus lebih atau OCR (Over Current Relai) memproteksi transformator daya terhadap gangguan antar phasa. Sedangkan untuk memproteksi gangguan phasa tanah digunakan relai arus gangguan tanah atau GFR. Prinsip kerja GFR sama dengan OCR, yang membedakan hanyalah pada fungsi dan elemen sensor arus. Pada OCR biasanya memiliki 2 atau 3 sensor arus (untuk 2 atau 3 phasa), sedangkan pada GFR hanya memiliki satu sensor arus (satu phasa).

\section{Metode Analisis}

Penelitian dilakukan di PT. PLN (Persero) P3B Area Pelaksana Pemeliharaan Bali Gardu Induk Kapal, Indonesia pada transformator 3 dengan daya 60 MVA yang dimulai dari bulan Agustus 2015. Data-data dalam pembahasan penelitian ini bersumber dari PT. PLN (Persero) P3B Area Pelaksana Pemeliharaan Bali Gardu Induk Kapal, Indonesia.

Adapun alur analisis pada penelitian ini yaitu penginputan data, proses perhitungan dan analisis koordinasi GFR :

A. Input Data

1) Data arus hubung singkat trafo 3 GI Kapal

2) Data setting GFR bus dan GFR saluran

3) Data transformator 3 di GI Kapal

B. Menghitung nilai impedansi hubung singkat, impedansi trafo, gangguan hubung singkat 1 phasa ke tanah serta setting arus dan waktu pada OCR dan GFR dilakukan dalam beberap tahapan sebagai berikut [5] :

1) Impedansi Hubung Singkat :

$$
\mathrm{Z}_{\mathrm{hs}}=\frac{V_{p}}{\sqrt{3} \cdot \mathrm{I}_{\mathrm{hs}}}
$$

2) Impedansi trafo:

$$
\mathrm{Z}_{\mathrm{tr}}=\frac{V_{p}^{2} \cdot Z_{t}}{\frac{P}{1000}}
$$

3) Ihs $1 \varnothing$ pada sisi $20 \mathrm{kV}$ :

$$
\mathrm{I}_{1 \varnothing 20}=\frac{V_{S} \cdot 1000}{\sqrt{3} \cdot N G R}
$$

I Gede Krisnayoga Kusuma : Studi Analisa Koordinasi Relai...
4) Setting Arus dan Waktu pada OCR dan GFR Sisi Penyulang $20 \mathrm{kV}$ [5] :

Setting arus OCR pada sisi penyulang

Iset $_{\text {peny }}=\frac{1,2 \cdot I_{\text {peny }}}{\mathrm{CT}}$

Setting waktu OCR pada sisi penyulang

$T_{d}=\frac{\left(\frac{\mathrm{I} \not \emptyset 20}{I s p e n y}\right)^{0,02}-1}{0,14} \cdot 0,25$

Setting arus GFR pada sisi penyulang

$\mathrm{Ig}_{\text {peny }}=\frac{0,2 \cdot \mathrm{I}_{\text {peny }}}{\mathrm{CT}}$

Setting waktu GFR pada sisi penyulang peguyangan

$\mathrm{T}_{\mathrm{d}}=\frac{\left(\frac{\mathrm{I}_{\text {Ingr }}}{\text { Ipgeny }}\right)^{0,02}-1}{0,14} \cdot 0,25$

5) Setting Arus dan Waktu pada OCR dan GFR Sisi Incoming $20 \mathrm{kV}$ [5] :

Setting arus OCR pada sisi incoming $20 \mathrm{kV}$

$\mathrm{I}_{\mathrm{ss}}=\frac{1,2 \cdot I_{S}}{C T}$

Setting waktu OCR pada sisi incoming $20 \mathrm{kV}$

$T_{d}=\frac{\left(\frac{13 \varnothing 20}{I_{S S 1}}\right)^{0.02}-1}{0,14} \cdot 0,3$

Setting arus GFR pada sisi incoming $20 \mathrm{kV}$

$\mathrm{I}_{\mathrm{ssg}}=\frac{0,2 \cdot \mathrm{I}_{1} \varnothing_{20}}{\mathrm{CT}}$

Setting waktu GFR pada sisi incoming $20 \mathrm{kV}$

$\mathrm{T}_{d}=\frac{\left(\frac{\left(11 \varnothing_{20}\right.}{I_{S S 1}}\right)^{0.02}-1}{0.14} \cdot 0,5$

C. Analisis koordinasi setting pada OCR dan GFR pada gangguan hubung singkat di penyulang Peguyangan

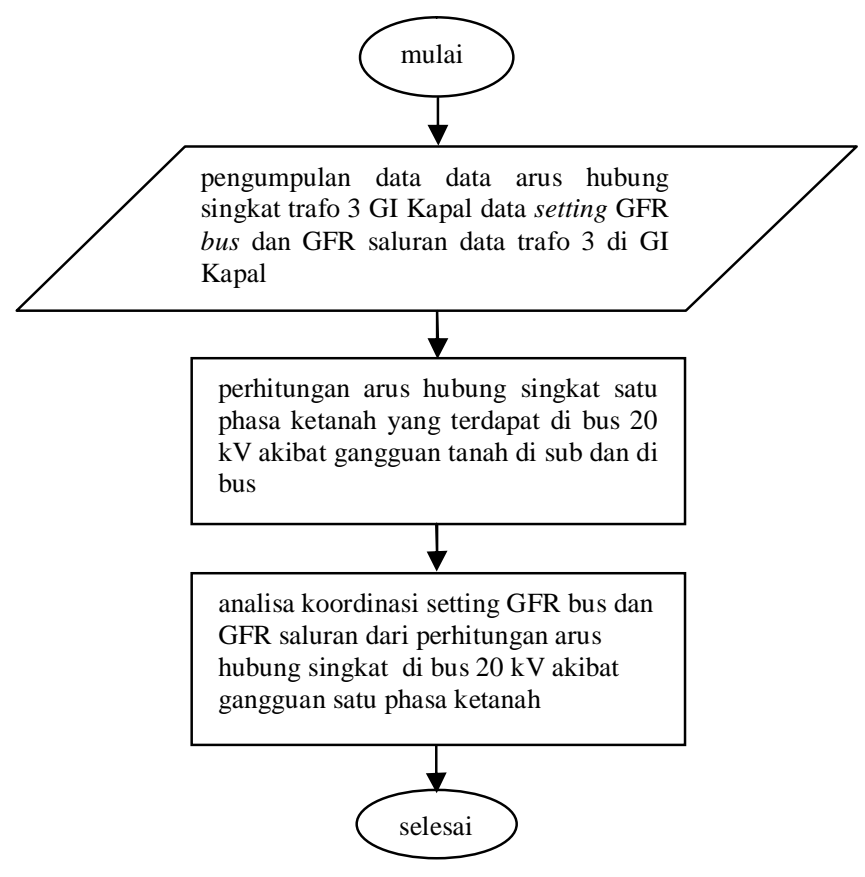

Gambar 1: Alur analisis

p-ISSN:1693 - 2951; e-ISSN: 2503-2372 


\section{HASIL DAN PEMBAHASAN}

A. Setting Pengaman Transformator 3 di Gardu Induk Kapal

Menganalisa koordinasi relai GFR incomming busbar 20 $\mathrm{kV}$ dan GFR saluran diperlukan nilai dari daya trafo, impedansi, trafo arus, arus nominal sisi primer dan sekunder serta arus hubung singkat bus $150 \mathrm{kV}$ di transformator 3 Gardu Induk Kapal.

Data Trafo Tenaga

$$
\begin{array}{llc}
\text { Type } & : \text { ORF 60/275 } & \\
\text { Daya (S) } & : 60000 \mathrm{kVA} & \\
\text { Tegangan } & : \mathrm{V}_{\mathrm{p}}: 150 \mathrm{kV} & \mathrm{V}_{\mathrm{s}}: 20 \mathrm{kV} \\
\text { Impedansi } & : \mathrm{Z}_{\mathrm{t}}: 12.49 \% & \\
\text { NGR } & : 40 \Omega & \\
\text { Trafo Arus } & : \mathrm{CT}_{\mathrm{p}}=\frac{400}{5} \mathrm{~A} \quad \mathrm{CT}_{\mathrm{s}}=\frac{2000}{5} \mathrm{~A} \\
\text { I Nom Trafo } & : \mathrm{I}_{\mathrm{p}}=\frac{\mathrm{s}}{\mathrm{V}_{\mathrm{p}} \cdot \sqrt{3}} \quad \mathrm{Ip}=230,9 \mathrm{~A} \\
& \mathrm{I}_{\mathrm{s}}=\frac{\mathrm{s}}{\mathrm{V}_{\mathrm{s}} \cdot \sqrt{3}} \quad \text { Is }=1732 \mathrm{~A}
\end{array}
$$

Arus hubung singkat di Bus $150 \mathrm{kV}$ ( Nilai Ihs total ) $\mathrm{I}_{\mathrm{hs}}=11,8648 \mathrm{Ka}$

\section{B. Perhitungan Arus Hubung Singkat di Penyulang $20 \mathrm{kV}$}

Untuk mendapatkan nilai dari arus hubung singkat maka di perlukan nilai dari perhitungan impedansi hubung singkat sesuai dengan persamaan (1) dan impedansi trafo sesuai dengan persamaan (2) dimana sistem dalam keadaan seimbang :

Impedansi Hubung Singkat: $\mathrm{Z}_{\mathrm{hs}}=\frac{V_{p}}{\sqrt{3} \cdot \mathrm{I}_{\mathrm{hs}}}$

$$
=\frac{150}{\sqrt{3} \cdot 11,8648}=7,3 \Omega
$$

Impedansi trafo

$$
\begin{aligned}
: \mathrm{Z}_{\mathrm{tr}} & =\frac{V_{p}^{2} \cdot Z_{t}}{\frac{P}{1000}} \\
& =\frac{150^{2} \cdot 0,1249}{\frac{60000}{1000}}=46,84 \Omega
\end{aligned}
$$

Arus hubung singkat satu phasa ketanah pada sisi $20 \mathrm{kV}$

$$
\begin{aligned}
: \mathrm{I}_{1 \varnothing 20} & =\frac{V_{S} \cdot 1000}{\sqrt{3} \cdot N G R} \\
& =\frac{20 \cdot 1000}{\sqrt{3} \cdot 40}=288,675 \mathrm{~A}
\end{aligned}
$$

\section{Setting Arus dan Waktu pada OCR dan GFR Sisi} Penyulang $20 \mathrm{kV}$

Untuk setelan relai yang terpasang di penyulang dihitung berdasarkan arus beban maksimum. Untuk relai inverse biasa diset sebesar 1,05 sampai dengan 1,1 x Imaks, sedangkan untuk relai definite diset sebesar 1,2 sampai dengan 1,3 $\mathrm{x}$ Imaks. Persyaratan lain yang harus dipenuhi yaitu untuk penyetelan waktu minimum dari relai arus lebih ( terutama di penyulang tidak lebih besar dari 0,3 detik ). Keputusan ini diambil agar relai tidak sampai trip lagi akibat adanya arus inrus dari trafo-trafo distribusi yang sudah terpasang di jaringan distribusi, pada saat PMT penyulang tersebut di masukan.

1) Setting arus OCR pada sisi penyulang :
Nilai setting OCR pada sisi penyulang dapat dicari dengan menggunakan persamaan (4), didapatkan nilai pada sisi penyulang Peguyangan :

$$
\begin{gathered}
\mathrm{I}_{\text {peny }}=300 \mathrm{~A} \quad \mathrm{CT}=\frac{600}{5} \mathrm{~A} \\
\text { Iset }_{\text {peny }}=\frac{1,2 \cdot \mathrm{I}_{\text {peny }}}{\mathrm{CT}} \\
=\frac{1,2 \cdot 300}{600 / 5}=3 \mathrm{~A}
\end{gathered}
$$

Nilai yang di pilih merupakan nilai yang di sesuaikan dengan range dari alat pengaman terebut.

$$
\begin{aligned}
\mathrm{I}_{\text {penymom }} & =11,47 \cdot \mathrm{Is}_{\text {peny }} \\
& =11,47 \cdot 360=4,129 \times 10^{3} \mathrm{~A} \\
\mathrm{Is}_{\text {mompeny }}= & \frac{\mathrm{I}_{\text {penymom }}}{\mathrm{CT}} \\
& =\frac{4,129 \times 10^{3}}{600 / 5}=34,93 \mathrm{~A}
\end{aligned}
$$

Tpenymoments $:=0,3$ detik

\section{2) Setting waktu OCR pada sisi penyulang:}

Waktu kerja OCR pada sisi penyulang dapat dicari sesuai dengan persamaan (5), didapatkan waktu kerja sisi penyulang Peguyangan :

$$
T_{d}=\frac{\left(\frac{11,997 \times 10^{3}}{360}\right)^{0,02}-1}{0,14} \cdot 0,25=0,130 \text { dipilih } T_{d}=0,13 \mathrm{SI}
$$

Nilai yang di pilih merupakan nilai yang di sesuaikan dengan range dari alat pengaman tersebut.

$$
\begin{aligned}
& \text { Waktu actual: } \text { Tpenyact }=\frac{0,14}{\left(\frac{13 \varnothing 20}{\text { Ispeny }}\right)^{0,02}-1} \cdot \mathrm{T}_{\mathrm{d}} \\
& \qquad=\frac{0,14}{\left(\frac{11,997 \times 10^{3}}{360}\right)^{0,02}-1} \cdot 0,13=0,25 \text { detik }
\end{aligned}
$$

3) Setting arus GFR pada sisi penyulang :

Nilai setting GFR pada sisi penyulang dapat dicari dengan menggunakan persamaan (6), didapatkan nilai pada sisi penyulang Peguyangan :

$$
\operatorname{Ig}_{\text {peny }}=\frac{0,2 \cdot 300}{600 / 5}=0,5 \mathrm{~A} \text { dipilih } \operatorname{Ig}_{\text {peny }}=0,5 \mathrm{~A}
$$

Nilai yang di pilih merupakan nilai yang di sesuaikan dengan range dari alat pengaman terebut.

4) Setting waktu GFR pada sisi penyulang Peguyangan:

Waktu kerja GFR pada sisi penyulang dapat dicari sesuai dengan persamaan (7), didapatkan waktu kerja sisi penyulang Peguyangan :

$$
\mathrm{T}_{\mathrm{d}}=\frac{\left(2 \frac{288,66}{50}\right)^{0,02}-1}{0,14} \cdot 0,25=0,064 \text { dipilih } \mathrm{T}_{\mathrm{d}}=0,06 \mathrm{SI}
$$

Nilai yang di pilih merupakan nilai yang di sesuaikan dengan range dari alat pengaman tersebut.

$$
\begin{aligned}
\text { Waktu actual }: \mathrm{Tg}_{\text {penyact }} & =\frac{0,14}{\left(\frac{\mathrm{I}_{\text {ggr }}}{\text { Ipgpeny }}\right)^{0,02}-1} \cdot \mathrm{T}_{\mathrm{d}} \\
& =\frac{0,14}{\left(\frac{288.66}{50}\right)^{0,02}-1} \cdot 0,06=0,25 \text { detik }
\end{aligned}
$$


D. Setting Arus dan Waktu pada OCR dan GFR Sisi Incoming $20 \mathrm{kV}$

Berdasarkan hasil perhitungan nilai setting arus dan waktu pada OCR dan GFR sisi incoming $20 \mathrm{kV}$ dapat dilihat pada perhitungan sebagai berikut :

1) Setting arus OCR pada sisi incoming $20 \mathrm{kV}$ :

Nilai setting OCR pada sisi incoming $20 \mathrm{kV}$ dapat dicari dengan menggunakan persamaan (8), didapatkan nilai pada sisi incoming $20 \mathrm{kV}$ :

$$
\mathrm{I}_{\mathrm{ss}}=\frac{1,2 \cdot 1,732 \times 10^{3}}{2000 / 5}=5,196 \mathrm{~A} \quad \text { di pilih }=5,2 \mathrm{~A}
$$

Nilai yang di pilih merupakan nilai yang di sesuaikan dengan range dari alat pengaman terebut.

Ismoment $=4$. Is

$$
\begin{aligned}
& =4.1,732 \times 10^{3}=6,928 \times 10^{3} \mathrm{~A} \\
I S_{\text {moment }} & =\frac{I p_{\text {momen }}}{C T} \\
& =\frac{6,928 \times 10^{3}}{2000 / 5}=17,32 \mathrm{~A}
\end{aligned}
$$

2) Setting waktu OCR pada sisi incoming $20 \mathrm{kV}$ :

Waktu kerja OCR pada sisi incoming $20 \mathrm{kV}$ dapat dicari sesuai dengan persamaan (9), didapatkan waktu kerja sisi incoming $20 \mathrm{kV}$ :

$$
T_{d}=\frac{\left(\frac{11.997 \times 10^{3}}{2,08 \times 10^{3}}\right)^{0.02}-1}{0.14} \cdot 0,3=0,076 \operatorname{dipilih} T_{d}=0,08 \mathrm{SI}
$$

Nilai yang di pilih merupakan nilai yang di sesuaikan dengan range dari alat pengaman terebut.

$$
\text { Waktu actual : } \begin{aligned}
T_{a c t} & =\frac{0,14}{\left(\frac{13 \emptyset 20}{I_{S S} 1}\right)^{0.02}-1} \cdot T_{d} \\
& =\frac{0.14}{\left(\frac{11,997 \times 10^{3}}{2,08 \times 10^{3}}\right)^{0.02}-1} \cdot 0,08=0.3 \text { detik }
\end{aligned}
$$

3) Setting arus GFR pada sisi incoming $20 \mathrm{kV}$ :

Nilai setting GFR pada sisi incoming $20 \mathrm{kV}$ dapat dicari dengan menggunakan persamaan (10), didapatkan nilai pada sisi incoming $20 \mathrm{kV}$ :

$$
\begin{aligned}
\mathrm{I}_{\mathrm{ssg}} & =\frac{0,2 \cdot \mathrm{I}_{1} \varnothing_{20}}{\mathrm{CT}} \\
& =\frac{0,2 \cdot 288,675}{2000 / 5}=0,144 \mathrm{~A} \text { dipilih } \mathrm{I}_{\mathrm{ssg}}=0.1 \mathrm{~A}
\end{aligned}
$$

Nilai yang di pilih merupakan nilai yang di sesuaikan dengan range dari alat pengaman terebut.

4) Setting waktu GFR pada sisi incoming $20 \mathrm{kV}$ :

Waktu kerja GFR pada sisi incoming $20 \mathrm{kV}$ dapat dicari sesuai dengan persamaan (11), didapatkan waktu kerja sisi incoming $20 \mathrm{kV}$ :

$$
\mathrm{T}_{d}=\frac{\left(\frac{288,675}{40}\right)^{0.02}-1}{0,14} \cdot 0,5=0,144 \text { dipilih }=0,14 \mathrm{SI}
$$

Nilai yang di pilih merupakan nilai yang di sesuaikan dengan range dari alat pengaman tersebut.

$$
\text { Waktu actual }: T_{\text {act }}=\frac{0,14}{\left(\frac{\mathrm{I} 1 \varnothing_{20}}{I_{S S 1}}\right)^{0.02}-1} \cdot T_{d}
$$

I Gede Krisnayoga Kusuma : Studi Analisa Koordinasi Relai...

$$
=\frac{0,14}{\left(\frac{288,675}{40}\right)^{0.02}-1} \cdot 0,14=0,5 \text { detik }
$$

E. Analisis Hasil Perbandingan

1) Hasil perhitungan setting arus relai OCR dan GFR :

Berdasarkan perhitungan arus hubung singkat sesuai dengan persamaan 2.12 didapat hasil arus hubung singkat 3 phasa di sisi $150 \mathrm{kV}=\frac{150 \cdot 1000}{\sqrt{3} \cdot(7,3+46,84)}=1599,6 \mathrm{~A}$. Untuk hasil arus hubung singkat 3 phasa di sisi $20 \mathrm{kV}$ sampai dengan arus hubung singkat 1 phasa ketanah diperoleh hasil seperti pada table I di bawah.

TABEL I

HASIL PERHITUNGAN DARI ARUS Hubung SingKat

\begin{tabular}{|c|l|c|}
\hline No. & \multicolumn{1}{|c|}{ perhitungan } & transformator 60 MVA \\
\hline 1 & $\mathrm{I}_{\mathrm{hs}} 3$ phasa di sisi $150 \mathrm{kV}$ & $1599,6 \mathrm{~A}$ \\
\hline 2 & $\mathrm{I}_{\mathrm{hs}} 3$ phasa di sisi $20 \mathrm{kV}$ & $11,997 \times 10^{3} \mathrm{~A}$ \\
\hline 3 & $\mathrm{I}_{\mathrm{hs}} 2$ phasa di sisi $150 \mathrm{kV}$ & $1385,3 \mathrm{~A}$ \\
\hline 4 & $\mathrm{I}_{\mathrm{hs}} 2$ phasa di sisi $20 \mathrm{kV}$ & $10,390 \times 10^{3} \mathrm{~A}$ \\
\hline 5 & $\mathrm{I}_{\mathrm{hs}} 1$ phasa ketanah & $288,675 \mathrm{~A}$ \\
\hline
\end{tabular}

Berdasarkan perhitungan setting arus OCR penyulang peguyangan sesuai dengan persamaan (4) dimana Iset = $\frac{1,2 \cdot 300}{600 / 5}=3$ A. Berdasarkan persamaan (8) untuk mencari setting arus OCR sisi incoming $20 \mathrm{kV}$, serta berdasarkan persamaan (5) dan (9) untuk mencari setting waktu pada OCR penyulang peguyangan dan OCR sisi incoming $20 \mathrm{kV}$ diperoleh hasil seperti pada table II di bawah.

TABEL II

HASIL PERhitungan SetTing ARUs OCR PENYUlang DAN INCOMING 20 KV

\begin{tabular}{|c|c|c|c|}
\hline \multirow{2}{*}{ No. } & \multirow{2}{*}{ Perhitungan } & \multicolumn{2}{|c|}{ OCR } \\
\cline { 3 - 4 } & & Penyulang & Incoming $20 \mathrm{kV}$ \\
\hline 1 & Iset & $3 \mathrm{~A}$ & $5,2 \mathrm{~A}$ \\
\hline 2 & $\mathrm{I}_{\text {moment }}$ & $34,93 \mathrm{~A}$ & $17,32 \mathrm{~A}$ \\
\hline 3 & Td & $0,13 \mathrm{SI}$ & $0,08 \mathrm{SI}$ \\
\hline 4 & Tact & 0,25 detik & 0,3 detik \\
\hline
\end{tabular}

Perhitungan setting arus pada GFR penyulang peguyangan berdasarkan persamaan (6) dimana $\mathrm{Ig}=$ $\frac{0,2 \cdot 300}{600 / 5}=0,5$ A. Dengan persamaan (10) untuk mencari setting arus pada GFR sisi incoming $20 \mathrm{kV}$ serta persamaan (7) dan (11) untuk mencari setting waktu pada GFR penyulang peguyangan dan GFR sisi incoming $20 \mathrm{kV}$ diperoleh hasil seperti pada table III di bawah.

p-ISSN:1693 - 2951; e-ISSN: 2503-2372 
TABEL III

HASIL PERHITUNGAN SETTING ARUS DAN WAKTU GFR PENYULANG DAN INCOMING $20 \mathrm{KV}$

\begin{tabular}{|c|c|c|c|}
\hline \multirow{2}{*}{ No. } & \multirow{2}{*}{ Perhitungan } & \multicolumn{2}{|c|}{ GFR } \\
\hline & & Penyulang & Incoming $20 \mathrm{kV}$ \\
\hline 1 & $\mathrm{Ig}$ & $0,5 \mathrm{~A}$ & $0,1 \mathrm{~A}$ \\
\hline 2 & $\mathrm{Td}$ & $0,06 \mathrm{SI}$ & $0,14 \mathrm{SI}$ \\
\hline 3 & Tact & 0,25 detik & 0,5 detik \\
\hline
\end{tabular}

\section{2) Analisis Perhitungan Ground Fault Relay:}

Perhitungan setting relai gangguan tanah (Ground Fault) dengan karakteristik standar inverse di atas, nilai waktu tunda (Td/Time dial ) sesuai dengan table 4.3 didapat hasil pada sisi penyulang sebesar 0,06 SI dan pada sisi incoming $20 \mathrm{kV}$ sebesar 0,14 SI setelah diuji/diperiksa waktu kerja relai gangguan tanah di penyulang Peguyangan sesuai table III menunjukkan bahwa waktu untuk relai bekerja adalah selama 0,25 detik sesuai dengan yang diharapkan pada waktu actual. Sementara waktu kerja relai gangguan tanah di incoming 20 $\mathrm{kV}$ selama 0,5 detik. Ini menandakan bahwa perbedaan waktu kerja relai sebesar 0,25 detik sudah dianggap selektif.

Gangguan satu phasa ke tanah terjadi pada penyulang Peguyangan, dimana penyulang Peguyangan memiliki arus nominal sekunder (Is) sebesar 1732,1 A. Arus gangguan yang terjadi sewaktu gangguan satu phasa ke tanah dirasakan juga oleh relai gangguan tanah pada sisi $20 \mathrm{kV}$ sehingga memadamkan seluruh penyulang yang di suplai oleh trafo 3 gardu induk kapal. Pada sistem kondisi normal gangguan satu phasa pada penyulang akan dirasakan dan diamankan oleh relai gangguan tanah pada penyulang agar daerah gangguan tidak meluas dan daerah pemadaman dapat di perkecil, sehingga penyulang lain yang di suplai oleh trafo 3 gardu induk kapal tidak terjadi pemadaman saat terjadi gangguan satu phasa ketanah.

Gangguan satu phasa ketanah yang terjadi pada 24 Januari 2013 di penyulang peguyangan dengan besar arus gangguan 1800 A. Gangguan yang terjadi seharusnya diamankan oleh relai gangguan tanah pada penyulang. Namun karena peralatan mengalami malfuntion, sehingga relai gangguan tanah yang terpasang di incoming busbar $20 \mathrm{kV}$ tersebut mendeteksi juga gangguan tanah pada penyulang yang kemudian memerintahkan PMT sisi $20 \mathrm{kV}$ membuka sehingga mengakibatkan pemadaman keseluruh penyulang yang di suplai oleh trafo 3 gardu induk Kapal.

\section{Kesimpulan}

Berdasarkan table diatas, maka didapat beberapa kesimpulan yaitu sebagai berikut :

Analisis dari hasil perhitungan OCR pada penyulang peguyangan dengan kapasitas CT rasio 600/5 dengan nilai arus 360 A sedangkan pada sisi incoming busbar $20 \mathrm{kV}$ dengan nilai arus 624 A. Untuk setting waktu actual yang didapat pada penyulang selama 0,25 detik dan pada sisi incoming busbar $20 \mathrm{kV}$ didapat selama 0,3 detik. Ini menandakan bahwa perbedaan waktu kerja relai sebesar 0,05 detik sudah dianggap selektif.

Koordinasi relai gangguan tanah memperoleh hasil pengamanan secara bertahap, dimana semakin keujung saluran waktu pengamanan yang diperlukan semakin kecil. Ini bertujuan agar daerah gangguan dapat diminimalkan. Perhitungan GFR di transformator 60 MVA menghasilkan nilai setting waktu actual pada penyulang selama 0,25 detik sedangkan pada sisi incoming busbar $20 \mathrm{kV}$ didapat setting waktu actual selama 0,5 detik. Ini menandakan bahwa perbedaan waktu kerja relai sebesar 0,25 detik sudah dianggap selektif.

Saran yang dapat penulis berikan pada skripsi ini adalah untuk menambah keakuratan perhitungan dari koordinasi setting relai pengaman akibat gangguan satu phasa ketanah perlu di perhitungkan rugi-rugi atau loses yang terdapat di peralatan pengaman agar pada saat perhitungan mendapatkan nilai yang akurat.

\section{REFERENSI}

[1] I. G. M. W. M. Sidemen, R. S. Hartati, and Linawati, "Peramalan Beban Listrik Harian dengan Metode Adaptive Neuro Fuzzy Inferrence System," Teknik Elektro, Vol. 13, No. 1 Januari - Juni 2014

[2] I. Baskara, I. W. Sukerayasa and W. G. Ariastina, "Studi Koordinasi Peralatan Proteksi OCR dan GFR pada Penyulang Tibubeneng," Teknik Elektro, Vol. 14, No. 2, Juli - Desember 2015

[3] Marsudi, D, Operasi Sistem Tenaga Listrik, Jakarta: Balai Penerbit dan Humas ISTN, 1990

[4] Sutarti,"Analisa Perhitungan Setting Arus Dan Waktu Pada Relai Arus Lebih (OCR) Sebagai Proteksi Trafo Daya Di Gardu Induk Cawang Lama Jakarta," Teknik Elektro, Sekolah Tinggi Teknologi Indragiri. 2012

[5] Komari, S. Soekarto, and Wirawan, Kaidah Umum Penyetelan Rele, PT. PLN (Persero), Semarang, Indonesia : 1995. 